\title{
Start-up investment with scarce venture capital support
}

\author{
Vesa Kanniainen ${ }^{\text {a,c }}$, Christian Keuschnigg b,c,d,* \\ ${ }^{a}$ University of Helsinki, P.O. Box 54, FIN-00014 University of Helsinki, Finland \\ ${ }^{\mathrm{b}}$ University of St. Gallen (IFF-HSG), Varnbuelstrasse 19, CH-9000 St. Gallen, Switzerland \\ ${ }^{\mathrm{c}}$ CESifo, Munich, Germany \\ ${ }^{\mathrm{d}}$ CEPR, London, UK
}

Received 11 November 2002; accepted 2 July 2003

Available online 9 January 2004

\begin{abstract}
Venture capitalists, representing informed capital, screen, monitor and advise start-up entrepreneurs. The paper reports three new results on venture capital (VC) finance and the evolution of the VC industry. First, there is an optimal VC portfolio size with a trade-off between the number of companies and the value of managerial advice. Second, advice tends to be diluted when the industry expands and VC skills remain scarce in the short-run. The delayed entry of experienced VCs eventually restores the quality of advice and leads to more focused company portfolios. Third, as a welfare result, VCs tend to provide too little advisory effort and to invest in too few companies. Testable implications are also discussed.
\end{abstract}

(c) 2003 Elsevier B.V. All rights reserved.

JEL classification: D82; G24; G32; L19

Keywords: Venture capital; Company portfolio; Managerial advice; Economic rents

\section{Introduction}

A professionally managed pool of venture capital funds with active managerial support has increasingly supplemented more traditional forms of financial intermediation in funding start-ups. Venture capitalists (VCs) represent informed capital, trying carefully to screen, select and monitor the projects they fund (Kaplan and

\footnotetext{
${ }^{*}$ Corresponding author. Tel.: +41-71-224-3085; fax: +41-71-224-2670.

E-mail address: christian.keuschnigg@unisg.ch (C. Keuschnigg).
} 
Strömberg, 2001). VC is not a new financial innovation. Xerox, Microsoft, and Netscape, among many, all obtained seed capital in their early state. The seminal papers (Gorman and Sahlman, 1989; Sahlman, 1990; Gompers, 1995; Lerner, 1995) indicated that VCs take a rather different role from other intermediaries not to mention passive equity participations. Given the often limited business competence of the founding entrepreneur, $\mathrm{VC}$ advice in building business relations, hiring the right personnel and marketing the product etc. becomes a key complementary expertise to entrepreneurial efforts. There are probably few industries where experience matters as much as in VC investing. Such competence arises from active business involvement in the respective industry. It cannot be acquired in short order, nor is it easily transferable. Citing Gompers and Lerner (1999, p. 4): "Not only is it difficult to raise a new venture capital fund without a track record, but the skills needed for successful venture capital investing are difficult and time-consuming to acquire". It is expected that the limited supply of informed VCs, rather than the availability of financial capital, is the scarce factor in launching innovative firms.

In markets with substantial information problems, VC companies play a valuable role in screening and guiding new start-ups, in monitoring the progress of projects and devoting resources to enhance their success. The early literature recognized and emphasized the need to monitor and limit opportunistic behavior under profit sharing arrangements (Gorman and Sahlman, 1989; Admati and Pfleiderer, 1994; Barry, 1994). Many studies have by now scrutinized optimal contracts that create proper incentives. A substantial literature explains what type of contracts may arise and how they deal with the double-sided moral hazard problem (Aghion and Tirole, 1994; Berglöf, 1994; Trester, 1998; Marx, 1998; Repullo and Suarez, 1999; Schmidt, 2002; Casamatta, 2002; Cornelli and Yosha, 2003). The main task has been to explain the observed extensive use of convertibles. Staging of capital infusion creates an option to abandon a disappointing project (Sahlman, 1990) and obtain new information (Gompers, 1995; Bergemann and Hege, 1998). Evidence on VC contracts so far exists mainly for the US. Kaplan and Strömberg (2000) have documented the predominant use of convertible instruments and the use of direct control rights (boards, voting rights, as analyzed by Hellmann (1998)).

In focusing on the real effects of $\mathrm{VC}$ in industry equilibrium, we adopt a simple static model of venture finance where straight common equity is the optimal financial contract. To rationalize a role for convertibles, we would have to allow for a more dynamic and considerably more complicated interaction between entrepreneurs and VCs. In a more dynamic framework, the optimality of securities depends on how the project knowledge of the investor relative to the investee changes as the project develops over different stages, see Garmaise (2000), for example. Although a subset of the literature suggests that convertibles are a more flexible instrument, they are, in fact, not intensively used in other countries outside the US. In Europe, Schwienbacher (2002), Bascha and Walz (2001) and Cumming (2002) find that convertibles are adopted infrequently in VC finance. Cumming (2001b) reports the same results for Canada. He shows, in particular, that US based VCs do not use convertible securities when they finance Canadian entrepreneurial firms. Moreover, Gilson and Schizer (2002) argue that there is a significant tax bias in favor of convertible preferred 
securities which helps to explain their predominant use in the US. Sandler (2001) shows, however, that the Canadian tax law neither favors nor discourages the use of convertible securities. Given the tax explanation proposed for the US and the evidence for other countries, we argue that our simpler framework with straight equity finance is quite suitable for the purpose of this paper.

In times of high returns, VCs are keen to finance more firms. While new funds are easily raised, it is more difficult to attract personnel with sufficient entrepreneurial experience, reputation and industry knowledge to advise start-up firms. The size of the company portfolio becomes relevant when the managerial resource is scarce. It is surely inefficient to concentrate effort on a single start-up only as much of the literature actually assumes. However, the value of advice tends to be diluted and the gains from expanding the size of the portfolio start to diminish. VC firms must thus confront the problem of how to allocate attention and advisory effort among their portfolio companies.

The mechanisms associated with company portfolios and equilibrium in VC finance have not been addressed in the literature. Kanniainen and Keuschnigg (2003b) have introduced the concept of an optimal portfolio of firms. This paper turns to the implications of the involved trade-off between portfolio size and quality of advice for the nature of the industry equilibrium. To this end, we first consider a short-run equilibrium where the number of VCs is fixed, leaving them to finance a variable number of companies each. The shortage of informed VC gives rise to rents which should eventually attract new VCs. The free entry of VCs in the long-run relaxes the managerial resource constraint. This distinction between short- and longrun equilibrium appeals to the notion of Gompers and Lerner (1999) that it takes time to develop the skills of successful VC investing.

Consistent with our theoretical results, Lerner (2002a) demonstrates econometrically that the impact of $\mathrm{VC}$ on innovation is some $15 \%$ lower during boom periods compared to normal industry periods. This difference is strongly statistically significant. VCs may be diluting their support by taking on too many companies in booming markets. A related question is how the accumulated experience of VCs affects the quality of their investments, leading to potential differences, say between European and US VC markets. Indeed, the availability of high quality VC is probably still a considerable bottleneck especially in Europe. Using econometric techniques to compare the performance of VC backed and other young firms listed on the Euro.nm stock markets, Bottazzi and Da Rin (2002) found that European VCs had little effect on growth, corporate strategy and job creation. Their results indicate that "the quality of European venture capital might be a more urgent issue than its sheer quantity". This contrasts sharply with the recent findings on the role of US VCs. In the US, VC backed firms engage in more radical product or process innovations and are found to be faster in developing their products and in bringing them to market, as compared to other start-ups. They have a higher rate of CEO turnover, reflecting faster professionalization (Hellmann and Puri, 2000, 2002). And they produce more and more valuable patents (Kortum and Lerner, 2000).

Since specialized managerial competence is acquired only through active business experience, the emergence of experienced VCs tends to be a slow process, making the 
supply of VCs rather inelastic in the short-run. This paper aims at a characterization of the evolution of the VC sector in industry equilibrium, taking account of the scarce supply of the managerial investment resource. Most of the existing analytic work, in contrast, has focused on the form of the optimal incentive contract, leaving aside an endogenous explanation of venture returns in industry equilibrium and an optimal portfolio of firms. Except for Inderst and Müller (2002), we know of no other studies on the equilibrium of the VC industry. ${ }^{1}$ The size of the company portfolio plays an important role in distinguishing the short- and long-run development of the sector.

The idea of informed capital advising and overseeing a portfolio of independent enterprises has not yet been analyzed formally, though it has been brought into attention repeatedly in the literature (Gorman and Sahlman, 1989; Sahlman, 1990; Gompers, 1995; Norton and Tenenbaum, 1993; Reid et al., 1997). Recently, Cumming (2001a) has provided information on 231 Canadian VC firms investing in 5323 companies. In his data, the average number of companies in first-round investments ranges from 5.4 for private VC firms up to 29.5 for labor sponsored VC corporations. Allowing for all investments in 1991-1998, the average portfolio size is 13.7 and 59.9 respectively. No previous study asked how many companies can effectively be financed when consulting is a costly activity. In spite of initial scale effects, a VC investor should avoid advising too many companies as its supporting role might subsequently deteriorate.

Among our results, we show how optimal second-best advice and profit sharing respond to economic rents and costs faced by the contracting partners. Most importantly, we prove that a unique optimal company portfolio exists, subject to a tradeoff between the number of firms advised and the advisory effort provided. We also carry out a full-scale comparative static analyses of industry equilibrium, showing how important demand and supply side shocks determine the industry's adjustment much in line with Lerner's (2002a) empirical account of the boom and bust periods of the VC industry. The dilution of advice plays an important role in this adjustment. We also show how past business experience, determining the quality of advice, interacts with the expansion of the VC industry. The paper yields important welfare and policy implications as well, and gives rise to a number of testable implications which are discussed in the concluding section.

The paper is organized as follows. In Section 2, we derive the incentive compatible contract and solve for the optimal managerial advice when a VC finances a portfolio of companies. Section 3 studies the optimal number of portfolio companies and emphasizes the key trade-off between portfolio size and riskiness of projects. Section 4 turns to the industry equilibrium. In the short-run, the number of VCs is fixed and each one finances a variable number of firms to satisfy demand for VC support. We discuss how the presence of rents attracts more VCs and then explore the industry equilibrium when free entry makes the supply of VCs elastic and the managerial re-

\footnotetext{
${ }^{1}$ These authors have an equilibrium search model of VC. They do not consider an optimal portfolio of firms and the role it plays in determining the quality of VC finance during the industry's expansion.
} 
source becomes more abundant. Section 5 provides a short summary with some concluding comments.

\section{The model}

Basic assumptions: Our model of venture capital focuses on the managerial contribution of the financier and emphasizes the importance of profit sharing arrangements to realign the incentives of entrepreneurs and financiers. We keep the model simple in other respects. Agents are risk neutral. All potential projects require a uniform start-up cost $I>0$ and have identical stochastic structure ex ante. An entrepreneur is able to handle one project only which we associate with a start-up firm. Starting a firm requires the entrepreneur to give up an income $w \geqslant 0$ which she could earn elsewhere. Having no own resources, she must ask a VC to pay for the start-up cost. Her main capital is a business idea and her technological knowledge. Since the entrepreneur tends to be commercially inexperienced in the early stages of her career, the managerial expertise of the VC becomes valuable. A VC, in turn, finances and advises a portfolio of $n$ firms and must allocate her limited managerial capacity appropriately across firms to maximize value.

We thus assume that a project or firm is either successful and yields a return $R>0$, or is a failure and yields nothing. Complete failure is quite common among innovative start-up firms with yet untested products. The probability of success is independent across projects. It depends on effort $e_{i} \in\{0,1\}$ of the entrepreneur which can be either high or low, and on advice $a_{i} \geqslant 0$ that the VC allocates to the $i$ th project:

$$
P\left(e_{i}, a_{i}\right)=e_{i} p\left(a_{i}\right), \quad p^{\prime \prime}\left(a_{i}\right)<0<p^{\prime}\left(a_{i}\right), \quad p\left(a_{i}\right)<1, \quad A=\sum_{i=1}^{n} a_{i} .
$$

In practice, VCs are engaged in a variety of activities which add value to the firm. They provide administrative, financial, marketing and strategic advice. They also facilitate the exit process through finding a strategic acquiror, or through timing the initial offering on a public market. VCs often have networks of legal and accounting advisors and other consultants that can assist the start-up firm.

We assume diminishing returns to advice per project over the relevant range of $a_{i}$. Because of the assumption of symmetry, total effort is $A=a n$. The assumption on the form of the success probability implies that entrepreneurial effort is the critical input. ${ }^{2}$ Without her effort and full commitment, the project is always a failure. In contrast, the VC's close involvement with the firm is more of a gradual matter. We assume an increasing and convex cost of the VC's advising effort $\gamma c(A)$ satisfying $c^{\prime}(A)>0>c^{\prime \prime}(A)$, where higher values of $\gamma>0$ indicate increased effort cost. Given

\footnotetext{
${ }^{2}$ Much of the tractability of the model rests on this assumption. In a considerably simpler framework without portfolio choice, Keuschnigg and Nielsen (2002) consider the case where both inputs are variable.
} 
discrete effort choice, the entrepreneur's effort cost is simply $l(e)=\{0, \beta\}, \beta>0$. The subsequent analysis is greatly simplified in assuming isoelastic functional forms:

$$
p(a)=\alpha \cdot \frac{a^{1-\theta}}{1-\theta}, \quad c(A)=\frac{A^{1+\varepsilon}}{1+\varepsilon}, \quad 0<\theta<1, \quad \varepsilon>0 .
$$

We interpret the parameter $\alpha$ as reflecting the VC's experience and industry knowledge. We take it for granted that a more experienced VC endowed with superior know how is more productive in advising her portfolio companies and achieves with the same effort a higher survival probability than a novice. The parameter $\theta$ measures the degree of decreasing returns to advice, and $\varepsilon$ the degree of cost progression.

Venture capital investing: Since entrepreneurs have no own resources, the $\mathrm{VC}$ is assumed to finance the entire start-up cost of a project. One should point out, however, that the seed capital in the early stage of a new project is typically not given by institutionalized VCs but often stems from business angels or family members. Moreover, syndication is a known empirical fact in many VC contracts (Lerner, 1994). ${ }^{3}$ To focus on the main message of our paper and to report those results not yet available in the existing literature, we choose to make appropriate simplifications wherever possible. In our interpretation, the success probability relates to a later stage when the project has passed the stage of seed financing and the entrepreneur has successfully located a VC. ${ }^{4}$

The $\mathrm{VC}$ is thus assumed to finance the project in exchange for a profit share $1-s_{i}$. She also supports the firm with managerial advice and adds value. She confronts a sequence of decisions as is illustrated by the following time line:

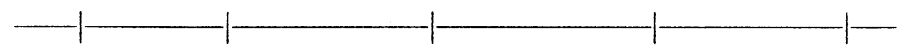

entry cost $c_{f}$ choose $n$ contract $s_{i}, b_{i}+I$ effort $e_{i}, a_{i}, A$ risk resolved

First, a VC decides whether to pay a fixed entry cost $c_{\mathrm{f}}$. Having established a fund, she then chooses the number of portfolio companies that she wants to finance and advise. Next, she proposes to buy a share $1-s_{i}$ of a new firm at a price $b_{i}+I$ that covers the start-up cost $I$ but also includes an upfront payment $b_{i}$ to the entrepreneur. In structuring the deal, the $\mathrm{VC}$ anticipates how the terms of the contract subsequently determine incentives for her own and the entrepreneur's effort. Given the terms of the contract, both parties next choose their joint effort levels which determine the survival probability. The level of effort is not verifiable and not contractible. The fact that the contract is fixed prior to effort choice creates a double sided moral hazard. Since effort is costly, the entrepreneur may be tempted to shirk if her profit share is too low. But also the VC's willingness to advise the firm depends

\footnotetext{
${ }^{3}$ Chemmanur and Chen (2001) propose a theoretical model with a choice between VC and angel financing over different financing rounds.

${ }^{4}$ Using a search model of the VC market, Keuschnigg (2003) indeed models the seed stage where VCs search for investments and entrepreneurs develop a business plan before approaching VCs.
} 
on the size of her equity stake and, thus, on her ability to share in the upside potential. Finally, risk is resolved and payments are made. We assume that there exists a well-defined exit option for a VC when the project return is realized. ${ }^{5}$

Our theoretical model assumes that VCs are homogenous. With heterogenous VCs, syndication of finance becomes attractive (cf. Lerner, 1994) and might in the aggregate increase the amount of VC finance available. Syndication would require another type of incentive structure to be included. Differences in the skill level and experience are known to result in restrictive covenants being imposed on inexperienced VCs by their limited partners (Gompers and Lerner, 1996, 1999; Lerner and Schoar, 2002). Such covenants possibly increase the efficiency of VC financing but are not included in our model where VCs are homogeneous and operate independently. Furthermore, the allocation of control rights is an important aspect of real world VC contracting to solve incentive problems. For theoretical work we refer to Aghion and Bolton (1992), Berglöf (1994) and Hellmann (1998) among others. Staging is another important method of VCs to control and monitor firms. It becomes relevant when information can be updated during the project, see Neher (1999). To sum up, actual VC contracts and governance structures tend to be more flexible than we assume in our static model. Kaplan and Strömberg (2001, p. 427) emphasize, however, that cash flow and control rights are more like complements rather than substitutes. We conclude that our simpler static model roughly captures the incentive problems between entrepreneurs and VCs.

Given these simplifications, the VC's overall problem is to maximize expected profits,

$$
\pi=\max _{s_{i}, b_{i}} \sum_{i=1}^{n}\left[e_{i} p\left(a_{i}\right)\left(1-s_{i}\right) R-b_{i}-I\right]-\gamma c(A)-c_{\mathrm{f}},
$$

subject to participation and incentive compatibility constraints,

$$
\begin{aligned}
& \mathrm{PC}^{E}: \Pi_{i}=e_{i} p\left(a_{i}\right) s_{i} R-l\left(e_{i}\right)+b_{i}-w \geqslant 0, \quad i=1, \ldots, n, \\
& \mathrm{IC}^{E}: p\left(a_{i}\right) s_{i} R-\beta \geqslant 0, \quad i=1, \ldots, n, \\
& \mathrm{IC}^{F}:\left\{a_{i}\right\}=\arg \max \sum_{i}\left[e_{i} p\left(a_{i}\right)\left(1-s_{i}\right) R\right]-\gamma c(A) .
\end{aligned}
$$

Condition (3i) is the participation constraint of entrepreneurs arising from occupational choice. In opting for an entrepreneurial career, she gives up an alternative wage income $w$. The contract must be generous enough to make entrepreneurship a worthwhile option. Conditions (3ii) and (3iii) reflect the ex post incentive constraints.

\footnotetext{
${ }^{5}$ There are five principal exit vehicles for a VC: IPO's, acquisitions, secondary sales, buybacks and write-offs (liquidations), cf. Cumming and MacIntosh (2003a,b). When VCs take greater control rights, VC investments are more likely to be exited through an acquisition than an IPO (Cumming, 2002). For theoretical work, we refer to Aghion and Bolton (1992), Berglöf (1994) and Aghion et al. (2000). Michelacci and Suarez (2002) point to the important role of stock markets in facilitating exit and thereby allowing for a faster recycling of informed capital.
} 
Given that investments are sunk and the contract is already specified, agents choose effort to maximize the remaining income that is still at their discretion. The minimum profit share $s_{i}$ that satisfies (3ii) and makes entrepreneurs willing to provide high effort, $e_{i}=1$, depends on the success probability and, thus, on the extent of managerial advice. On the other hand, shirking by the entrepreneur destroys any return to the VC's advisory effort in (3iii). Thus, the actions of entrepreneurs and the VC are importantly interactive.

\section{Venture capital investing}

\subsection{Managerial advice and profit sharing}

Effort: Following the time line in reverse order, we solve the model by backward induction. The necessary conditions for the VC's optimal advice to each firm are ${ }^{6}$

$$
\Omega_{i} \equiv e_{i} p^{\prime}\left(a_{i}\right)\left(1-s_{i}\right) R-\gamma c^{\prime}(A)=0, \quad i=1, \ldots, n .
$$

The efforts of the VC and all $n$ entrepreneurs are determined simultaneously. If $e_{i}^{*}=1$, then the VC provides a positive level of advice, $a_{i}^{*}>0$. If the entrepreneur shirks, $e_{i}^{*}=0$, the return to advice is negative, and the VC would not want to waste any effort, $a_{i}^{*}=0$. Joint efforts are thus complementary.

Financial contract: Optimal managerial advice as well as the entrepreneur's effort depend on the agreed profit shares. Anticipating how profit sharing shapes incentives, the VC chooses $s_{i}$ to maximize her profits. Suppose the entrepreneur's share is sufficiently high such that her incentive constraint (3ii) is slack. On account of the envelope theorem, the VC can raise her surplus in (3) by cutting the entrepreneur's profit share, ${ }^{7} \frac{\mathrm{d} \pi}{\mathrm{d} s_{i}}=-p\left(a_{i}^{*}\right) R<0$. She will do so until she hits the $\mathrm{IC}^{E}$ constraint which must therefore be binding in optimum. Consequently, conditions (3ii) and (4) jointly determine the optimal profit shares and managerial advice such that entrepreneurial effort is assured to be high. Since all projects are identical ex ante, we may concentrate on the symmetric solution.

Fig. 1 depicts the entrepreneur's and the financier's incentive constraints, respectively. ${ }^{8}$ The constraints intersect exactly two times. The profit maximizing solution is the lowest $s$ and, correspondingly, the highest $a$ as in point A of Fig. 1. With (3ii) binding, the entrepreneur's participation constraint (3i) reduces to $b_{i} \geqslant w$. The VC, of course, strives to purchase the stake $1-s_{i}$ at the lowest possible price $b_{i}+I$ that just succeeds to make the entrepreneur start the firm. Hence, the purchase price pays for the full investment cost but must also include an upfront payment $b_{i}=w$ that

\footnotetext{
${ }^{6}$ The second order conditions are fulfilled by $\Omega_{i i} \equiv e_{i} p^{\prime \prime}\left(1-s_{i}\right) R-\gamma c^{\prime \prime}<0$ and $\Omega_{i j} \equiv-\gamma c^{\prime \prime}<0$.

${ }^{7}$ Although varying $s_{i}$ leads her to adjust advice later at effort stage, this effect on $a_{i}$ is inconsequential for surplus due to (4).

${ }^{8}$ Fig. 1 draws on Kanniainen and Keuschnigg (2003b). A separate mathematical appendix, Kanniainen and Keuschnigg (2003a), also contains a formal analysis of Figs. 1 and 2, as well as the formal proofs for Tables 1 and 2 below.
} 


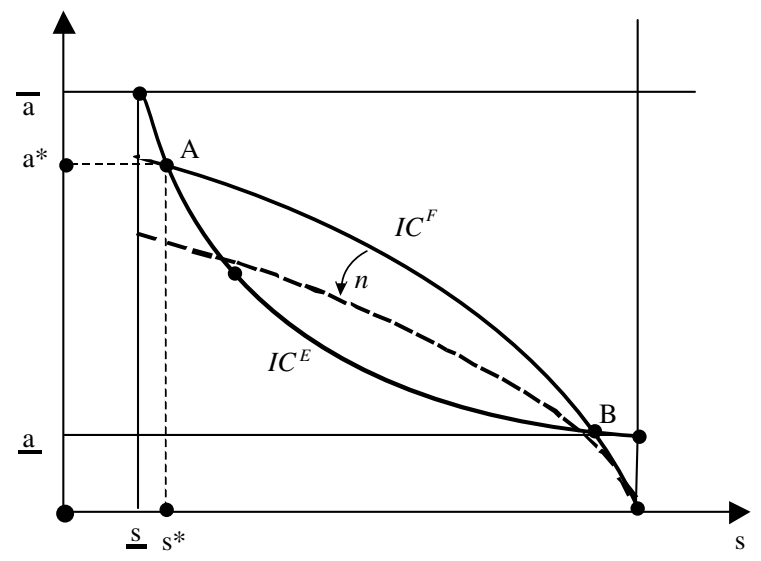

Fig. 1. Notation: $a$ managerial advice, $s$ equity share entrepreneur, $n$ number of portfolio firms, $\mathrm{IC}^{F}$ incentive constraint financier, $\mathrm{IC}^{E}$ incentive constraint entrepreneur.

compensates the entrepreneur for her foregone outside opportunities, but no more than that. ${ }^{9}$

Comparative statics: Fig. 1 demonstrates that a larger company portfolio tightens the VC's incentive constraint. In allocating her attention to a larger number of firms, she spends less time on each single project, even if she raises her overall managerial effort. Since less advice implies higher risk, she must cede a larger equity stake to entrepreneurs to enlist their full effort. With a lower share for her own, the VC will be able to extract a smaller profit from each firm in her portfolio. These will be important considerations in deciding about how many firms to finance and advise. Characterizing optimal portfolio size thus requires knowledge of the comparative statics of advice and incentive compatible equity shares. We are also interested in how venture returns, experience, effort costs and other parameters affect the nature of $\mathrm{VC}$ investing. We obtain the comparative statics in terms of logarithmic differentials, $\mathrm{d} \log a=\mathrm{d} a / a \equiv \hat{a}$, which are interpreted as percentage changes relative to an initial equilibrium position such as point A in Fig. 1. ${ }^{10}$ Using (2), the linearized incentive constraints (3ii) and (4) are

$$
\mathrm{IC}^{E}: \hat{s}=-\hat{R}-\hat{\alpha}-(1-\theta) \hat{a}, \quad \mathrm{IC}^{F}:(\theta+\varepsilon) \hat{a}=\hat{R}+\hat{\alpha}-\frac{s}{1-s} \hat{s}-\hat{\gamma}-\varepsilon \hat{n} .
$$

\footnotetext{
${ }^{9}$ Keuschnigg and Nielsen (2003) assume risk averse entrepreneurs. The fixed payment $b_{i}$ must then include a risk premium to compensate for risk bearing, on top of the outside wage.

${ }^{10}$ Using the hat notation, we obtain, for example, $\hat{p}=\frac{a}{p} \frac{\partial p}{\partial a} \cdot \hat{a}$ instead of the simple linearization $\mathrm{d} p=\frac{\partial p}{\partial a} \cdot \mathrm{d} a$. Logarithmic differentiation yields percentage changes $\mathrm{d} a / a \equiv \hat{a}$ instead of absolute changes $\mathrm{d} a$. The computations follow simple rules such as $\widehat{a b}=\hat{a}+\hat{b}, \widehat{a / b}=\hat{a}-\hat{b}$, or $\widehat{a^{b}}=b \hat{a}$. Constants drop out. We compute $\hat{p}=\hat{\alpha}+(1-\theta) \hat{a}$ from (2), for example. Logarithmic linearization uncovers complicated nonlinear interactions by solving linear equations. In Fig. 1, we replace the nonlinear curves by linear ones with the same slope at point $\mathrm{A}$, and explicitely solve for comparative static effects.
} 
Since effort costs increase progressively with the overall consulting activity $A=a n$, the VC optimally diverts attention and managerial support from the existing firms in her portfolio by $\hat{a}=-\frac{\varepsilon}{\theta+\varepsilon} \hat{n}$, when she decides to advise and finance additional startups. Higher effort cost $\gamma$ and a smaller equity share $1-s$ also discourage the consulting activity. As venture returns increase, however, the financier chooses to advise more intensively. The entrepreneur's equity share $\hat{s}$ may be cut if her incentives are strengthened by higher returns or by a higher success probability $\hat{p}=\hat{\alpha}+(1-\theta) \hat{a}$. Taking account of the simultaneity in (5), the equilibrium adjustment of advice is

$$
\hat{a}=\frac{1}{(1-s) \Psi}[\hat{R}+\hat{\alpha}-(1-s)(\hat{\gamma}+\varepsilon \hat{n})], \quad \Psi \equiv \theta+\varepsilon-(1-\theta) \frac{s}{1-s}>0 .
$$

According to (5), a higher project value directly raises the VC's incentives for consulting. In reducing risk, more advice allows to cut the incentive compatible profit share $s$. The implied increase in the financier's share reinforces her incentives for consulting which then allows for a further reduction in $s$. When this cycle converges, the total effect is positive, $\Psi>0$, and exceeds the direct effect. ${ }^{11}$ If consulting effort becomes more costly, the overall managerial activity $A$ and the advice per firm $a$ decline. The solution (6) points to a fundamental trade-off that a VC faces in financing additional start-up firms:

Lemma 1 (Dilution of Advice). Increasing the number of portfolio companies dilutes managerial advice and raises individual project risk.

Proof. By (6), $\hat{a}=\frac{-\varepsilon}{\Psi} \hat{n}$ which reduces the success rate by $\hat{p}=(1-\theta) \hat{a}$, see (2).

Substituting (6) back into the entrepreneur's constraint in (5) yields

$$
\hat{s}=\frac{1}{\Psi}[(1-\theta)(\hat{\gamma}+\varepsilon \hat{n})-(1+\varepsilon)(\hat{R}+\hat{\alpha})] .
$$

The intuition is revealed upon inspection of the entrepreneur's incentive constraint. A higher project value directly strengthens her incentives for high effort, allowing the VC to squeeze the profit share $s$. More interestingly, when the VC's effort cost or portfolio size increase, she must cede higher profit shares to entrepreneurs. In both cases, the VC advises less and thereby reduces the expected revenue of the project on account of a higher downside risk. She must then offer a higher profit share to enlist the entrepreneurs' full effort which is critical to retain survival chances. ${ }^{12}$

\footnotetext{
${ }^{11}$ The mathematical appendix shows that $\Psi>0$ is equivalent to $\mathrm{IC}^{E}$ being steeper than $\mathrm{IC}^{F}$ at point A of Fig. 1.

12 As Proposition $1 \mathrm{~b}$ states, there is a relation between the optimal contract and the VC's skill and experience. In our model, the skill of the $\mathrm{VC}$, interacting with the optimal contract, is captured by parameter $\alpha$. One might possibly argue that the more frequent use of convertibles in the US relative to Europe or Canada is related to investor skill and experience. This is clearly beyond the confines of this paper. Further theoretical and empirical work on investor skills, contracting practices and the provision of $\mathrm{VC}$ advice and effort is warranted.
} 
Proposition 1 (Advice and Profit Share). (a) Advice per firm falls with portfolio size $n$ and the VC's effort cost $\gamma$, but rises with return $R$ and productivity (experience) $\alpha$.

(b) The optimal profit share of the entrepreneur rises with portfolio size $n$ and effort cost $\gamma$, but falls with return $R$ and productivity $\alpha$.

Proof. Eqs. (6) and (7). Fig. 1 illustrates the effect of a larger portfolio.

\subsection{How many portfolio companies?}

The number of portfolio companies is optimal when the contribution of the marginal firm to expected overall profits is zero. Adding another firm to the portfolio shifts down the financier's incentive constraint as is illustrated in Fig. 1. Expanding the portfolio thus dilutes advice per firm, see Lemma 1, because the overall effort cost is increasing progressively with total managerial activity $A=a n$. In adding another firm, the VC thus raises project risk. Fig. 1 shows that she must therefore offer a higher profit share to entrepreneurs to enlist their full effort. The erosion of her own equity share impairs profits from inframarginal firms and eventually offsets the extra profit added by the marginal project. For a more formal proof, substitute $b_{i}=w$, differentiate (3) and impose symmetry to get ${ }^{13}$

$$
\pi_{n} \equiv \frac{\mathrm{d} \pi}{\mathrm{d} n}=[p(a)(1-s) R-w-I]-a \gamma c^{\prime}(n a)-n p(a) R \frac{\partial s}{\partial n} .
$$

Although a larger portfolio dilutes advice, the marginal effect on profits is zero by the envelope theorem applied to (3iii). The first term in square brackets indicates the contribution of an extra firm to expected VC profits. The second term reflects the additional effort cost from extending managerial support to the marginal firm. These two terms will be consolidated to a profit creation effect, net of the advising cost. The last term is a profit destruction effect. Having more firms leads the VC to advise each one less which erodes survival chances and returns to effort. To preserve incentives, the VC must cede a higher profit share to all her partners. ${ }^{14}$

Proposition 2 (Optimal Portfolio). A unique optimal number of portfolio companies exists, $0<n<\infty$.

\footnotetext{
${ }^{13}$ To avoid integer problems, we replace the summation by an integral and treat $n$ as continuous.

${ }^{14}$ If both efforts were continuous as in Keuschnigg and Nielsen (2002), backward solution would first determine efforts, $e(s)$ and $a(s)$. It would be in both parties' interest to choose $s$ such as to maximize joint surplus. Any distribution of the surplus is obtained by setting a suitable upfront payment $b$. If the VC advises a larger number of other firms, her input to each specific company becomes costlier. The firm should then rely more on the entrepreneur's effort which requires a higher profit share $s$, yielding $\mathrm{d} s / \mathrm{d} n>0$ as in the present case. We are thus convinced that the profit destruction effect as a main determinant of optimal portfolio size would remain in place even if we had continuous entrepreneurial effort. However, assuming $e$ to be discrete as in (1) greatly simplifies the analysis.
} 
Proof. Use $a p^{\prime}=(1-\theta) p$ from (2) and write (4) as $a \gamma c^{\prime}=(1-\theta)(1-s) p R$. Substitute into (8) and replace $p R$ by $\beta / s$ from (3ii) to obtain the net profit creation effect $z_{1}(s)$. Expand the last term in (8), $n p R \frac{\partial s}{\partial n}=s p R \frac{\hat{s}}{\hat{n}}$, use the elasticity noted in (7), $\hat{s}=\frac{(1-\theta) \varepsilon}{\Psi} \hat{n}$, and make use of (3ii) to also rewrite the profit destruction effect $z_{2}(s)$, the last term in (8). Noting that the equity share depends on the number of firms, $s(n)$ as in (7), the necessary condition for optimal portfolio size is

$$
\pi_{n}=z_{1}(s)-z_{2}(s)=0, \quad z_{1}(s) \equiv \theta \beta \frac{1-s}{s}-w-I, \quad z_{2}(s) \equiv \frac{(1-\theta) \varepsilon \beta}{\Psi(s)} .
$$

We have $z_{1}^{\prime}(s)<0$ and $z_{2}^{\prime}(s)>0$ since $\Psi^{\prime}(s)=-\frac{1-\theta}{(1-s)^{2}}<0$. Noting that $s$ increases with $n$ according to (7) gives the sufficient condition $\pi_{n n}<0$. Kanniainen and Keuschnigg (2003a,b) show that the functions $z_{1}(s)$ and $z_{2}(s)$ intersect, and $\pi_{n}$ crosses zero, within a well defined admissible interval $[\underline{s}, \bar{s}]$. The portfolio condition thus determines a share $s$ which is uniquely related to $n$ by Proposition $1 \mathrm{~b}$.

Noting that the equity share $s$ is an increasing function of $n$, Fig. 2 illustrates the solution for the optimal number of firms. The profit destruction effect becomes more severe as more firms are added to the portfolio and higher equity shares must be ceded to entrepreneurs. When the VC consolidates her portfolio, she advises rather more intensively and is able to appropriate a larger profit share without loosing the entrepreneur's effort. With small $n$, the profit creation effect (net of effort cost) of expanding the portfolio is then relatively high. It rapidly declines as more firms are included and the equity shares of all entrepreneurs in the portfolio have to be raised. The optimal number of portfolio firms is attained when the profit creation

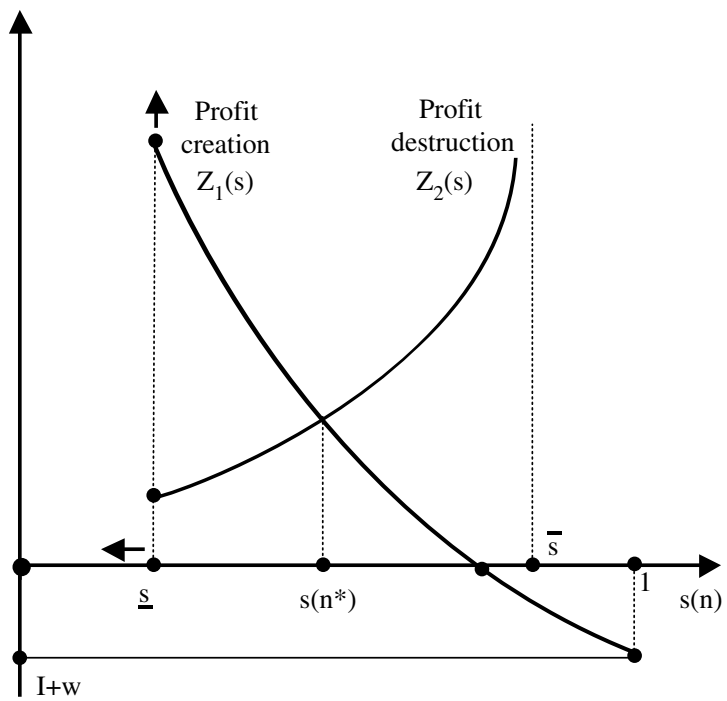

Fig. 2. Notation: $n$ number of portfoilo firms, $s$ equity share of entrepreneur, $I$ start-up investment cost, $w$ entrepreneur's outside wage. 
and destruction effects just cancel and the marginal firm fails to raise the VC's overall profits.

Both curvatures are important in determining portfolio size. With decreasing returns to advice $(0<\theta<1)$, it is better to advise more firms since a small amount of advice yields a big marginal effect $p^{\prime}$ on the success rate. When the VC concentrates on few firms only and advises very intensively, she is less effective in further raising the success probability since the marginal effect of advice becomes weaker. The concavity of the success probability works to expand portfolio size. With a convex cost function, however, the VC's effort cost increases progressively as more firms are added. Advice is stretched thin over many firms. Risks increase and expected venture returns decline, forcing the $\mathrm{VC}$ to cede higher profit shares to entrepreneurs which erodes her own profits. This profit destruction effect eventually makes a further expansion of the portfolio unattractive.

Proposition 3 (Effects on Portfolio). Optimal portfolio size rises with venture returns $R$ and managerial productivity $\alpha$ but falls with effort cost $\gamma$ and start-up cost $I$,

$$
\hat{n}=\zeta_{R}(\hat{\alpha}+\hat{R})-\zeta_{\gamma} \hat{\gamma}-\zeta_{I} \hat{I}
$$

where $\zeta$ are positive coefficients defined in (9b).

Proof. Note that $n$ enters the optimality condition $\pi_{n}=0$ in Proposition 2 only via its effect on $s$. Because of (7), the sufficient condition $\pi_{n n}=\frac{\partial \pi_{n}}{\partial s} \frac{\partial s}{\partial n}<0$ requires $\frac{\partial \pi_{n}}{\partial s}=-\frac{1}{s} \Omega<0$ with $\Omega$ given in (9a). Using this fact and taking the differential of $\pi_{n}=z_{1}(s)-z_{2}(s)=0$ yields $(9 \mathrm{a})$,

$$
\begin{aligned}
& \hat{s}=-\frac{I}{\Omega} \hat{I}, \quad \Omega=\frac{\beta(\theta+\delta)}{s}, \quad \delta=\varepsilon \cdot\left[\frac{s(1-\theta)}{(1-s) \Psi}\right]^{2}, \\
& \zeta_{R}=\frac{1+\varepsilon}{(1-\theta) \varepsilon}, \quad \zeta_{\gamma}=\frac{1}{\varepsilon}, \quad \zeta_{I}=\frac{I \Psi}{(1-\theta) \varepsilon \Omega} .
\end{aligned}
$$

Substituting (9a) into (7) gives (9) with coefficients listed in (9b).

Given how the minimum required equity share $s(n ; R, \alpha, \gamma)$ depends on portfolio size, as is stated in (7) in differential form, condition (8a) implicitely determines an optimal number of portfolio firms. The portfolio condition $z_{1}[s(n ; R, \alpha, \gamma), I]=$ $z_{2}[s(n ; R, \alpha, \gamma)]$ is illustrated in Fig. 2, with $n$ being listed on the horizontal axis. Consider now how VC portfolio size depends on key structural parameters such as a larger start-up cost $I$. Since the start-up cost is already sunk at effort stage, it cannot influence the incentives for effort and, thus, the minimum required equity share $s$. However, for any given $n$, it clearly diminishes the extra profit added from acquiring another firm which makes the VC less inclined to invest. The profit creation line $z_{1}$ thus shifts down in Fig. 2 while the profit destruction curve $z_{2}$ remains in place. The $\mathrm{VC}$ reduces the number of firms and offers a smaller profit share to entrepreneurs in 
exchange for more advice and lower risk. The new intersection in Fig. 2 occurs at a smaller number of portfolio companies.

Increases in venture returns $R$ or in managerial productivity $\alpha$ result in larger company portfolios. Higher returns strengthen incentives for advice. A higher upside potential raises expected returns which allows the VC to offer a smaller share $s$ and still enlist the entrepreneur's effort, see (6), (7). A smaller stake for the entrepreneur strengthens the profit creation effect of acquiring an additional firm. Since a larger number of portfolio firms dilutes advice for each individual one and thereby impairs the success probability, the VC must cede a higher required equity share to entrepreneurs. This profit destruction effect is less costly if the entrepreneur already receives a low share which suffices to reward her effort when returns are high. In Fig. 2, a higher venture return shifts up the $z_{1}$-schedule but shifts down the $z_{2}$-schedule. Both effects work to expand the company portfolio. ${ }^{15}$ Exactly the same logic applies to increased consulting productivity. A higher managerial effort cost $\gamma$ impairs the consulting activity and, thus, requires to raise the entrepreneur's share as in (6) and (7). With a lower share for her own, the VC finds the profit creation effect reduced and the profit destruction effect more powerful. The $z_{1}$-curve in Fig. 2 shifts down and the $z_{2}$-curve up, leading the $\mathrm{VC}$ to consolidate her portfolio of firms.

Finally, our results also help to explain how cost and productivity differences among VC firms affect portfolio size, managerial support, and profits. Suppose that effort cost increases, $\hat{\gamma}>0$, implying that one firm has higher managerial cost than another. Substituting (9) back into (6) gives $\hat{a}=-(\hat{\gamma}+\varepsilon \hat{n}) / \Psi=0$. A high cost VC fund thus advises each firm with the same intensity but simply deals with a smaller number of them. A high cost firm also earns smaller profits as can be checked from (B.7) of the mathematical appendix. In contrast, a VC with higher ability $\alpha$ chooses a larger portfolio in (9) and puts less hours to each firm. By the same steps, we get $\hat{a}=\frac{-1}{1-\theta} \hat{\alpha}$ and $\hat{p}=\hat{\alpha}+(1-\theta) \hat{a}=0$. Since she is more effective, she achieves with fewer hours the same success rate as a less experienced VC. According to (B.7), a more productive $\mathrm{VC}$ achieves higher profits.

\subsection{Efficiency}

Is there a bias towards inefficiently low VC support that might undermine the quality of private VC investing? It would be detrimental to the extent of advice and mentoring that start-up companies may expect. Since new entrepreneurs are often commercially inexperienced, lack of involvement undermines the prospects of start-up firms. An unfavorable bias would also imply that VC backed firms are not significantly different from other start-ups that rely on traditional sources of fi-

\footnotetext{
${ }^{15}$ The larger portfolio size offsets the direct effect on advice and profit sharing. Venture returns directly boost advice as in (6). The expansion of the VC portfolio, however, dilutes advice to an extent that managerial input per firm ends up being smaller. Substituting (9) into (6) and using $(1-s) \Psi=(1-s)(1+\varepsilon)-(1-\theta)$ yields $\hat{a}=-\hat{R} /(1-\theta)$. This keeps expected revenue $p R$ constant and satisfies (3ii) for a fixed $s$. Alternatively, substitute (9) into (7) and get a net effect on the profit share equal to zero as in (9a).
} 
nance. Furthermore, do VCs finance the right number of portfolio companies? We have argued that managerial advice is diluted when the VC's scarce managerial resource must be allocated to a larger number of portfolio companies. Hence, the two questions are importantly interrelated.

To investigate the existence of potential distortions in $\mathrm{VC}$ financing, we compare private decisions with an efficient allocation that maximizes the joint surplus without incentive constraints. By (3) and (3i), joint surplus is

$$
V=\pi+\sum_{i=1}^{n} \Pi_{i}=\sum_{i=1}^{n}\left[p\left(a_{i}\right) R-\beta-w-I\right]-\gamma c(A)-c_{\mathrm{f}} .
$$

The joint surplus internalizes the mutual externalities resulting from separate effort choices of the VC and the entrepreneurs. Maximizing it with respect to advice per firm and the number of entrepreneurs per VC yields a first best allocation which is characterized by

(a) $V_{a}=p^{\prime}\left(a_{i}\right) R-\gamma c^{\prime}(A)=0$,

(b) $V_{n}=\left[p\left(a_{n}\right) R-\beta-w-I\right]-\gamma a_{n} c^{\prime}(A)=0$.

Proposition 4 (Efficiency). Suppose the VC has optimally chosen $a, s$ and $n$. Joint surplus increases if VCs can be induced to finance a larger number of portfolio companies and to advise them more intensively.

Proof. Compare (11a,b) with (4) and (8a), and use (3ii). Evaluating the derivatives of the joint surplus at the private equilibrium allocation thus yields

(a) $V_{a}=p^{\prime}(a) R-\gamma c^{\prime}(A)=s p^{\prime}(a) R>0$,

(b) $V_{n}=p(a)(1-s) R-w-I=z_{1}(s)>0$.

The social gain from a VC financing an extra firm is equal to the profit creation effect which is positive on account of the private portfolio condition $z_{1}=z_{2}=\frac{(1-\theta) \varepsilon \beta}{\Psi(s)}$.

The proposition states that privately optimal advice and portfolio size are both smaller than what would be required to maximize joint surplus. The intuition is as follows. In private equilibrium, the entrepreneur must receive a share $s$ of project returns so that she supplies high effort. Otherwise, the venture would fail for sure. While profit sharing is incentive compatible, it also implies that the VC bears the full marginal cost but obtains only a share $1-s$ of the marginal benefit $p^{\prime}(a) R$ of her consulting activity. The rest accrues to the entrepreneur. This external benefit is internalized when maximizing joint surplus which considers the income gains to both parties. For a given number of firms $n$, the VC therefore provides a level of advice per firm smaller than what is efficient, $a<a^{*}$.

Consider next the number of firms in a VC's portfolio. The social gain from an additional firm is equal to the profit creation effect which is already net of both types of effort costs. The VC, however, considers only her own surplus and, therefore, subtracts the profit destruction effect to arrive at a privately optimal portfolio. This 
profit destruction effect results from the fact that managerial advice gets stretched thin on a larger portfolio. Since this undermines the venture's survival chance, the VC must cede a larger profit share to retain the entrepreneur's critical effort which subtracts from her own profits. From a social perspective, however, the profit destruction effect is a mere redistribution from the VC to entrepreneurs and, therefore, doesn't appear in the condition for an efficient portfolio in (11b). In face of these spillovers, VCs tend to invest in too few firms, $n<n^{*}$.

\section{Industry equilibrium}

We are particularly interested how certain structural parameters shape the nature and evolution of the VC industry. The model is thus closed by assuming that venture returns $R$ decline as more start-ups successfully mature to production stage. We also assume that there is no shortage of potential entrepreneurs as long as the reward from starting a business is sufficiently attractive. Neither is there a shortage of financial resources. In our view, the critical resource in the development of the VC industry is the managerial expertise and knowledge of experienced VCs. The specialized human capital of VCs isn't easily acquired but takes time to develop. To emphasize this point, we consider a short-run equilibrium where the number of VCs is fixed. The scarcity of the managerial resource should create rents which eventually attract new VCs who compete them away in the long-run equilibrium.

\subsection{Market demand and supply: How rents promote entry}

Successful VC investing requires much experience and rather specialized know how as well as detailed industry knowledge, all of which are difficult to acquire in short order. Keeping the number $N$ of VCs fixed in the short-run, we investigate how they adjust their portfolios to changing market conditions. The fixed supply of VCs may create rents that should attract other VCs to pay the entry $\cos c_{\mathrm{f}}$. As ever more VCs set up a fund, the expansion of the industry will eventually erode profit opportunities and make further entry unprofitable. A zero profit condition then determines the number of VCs in the long-run. The questions of how many VCs the industry is able to sustain, and how entry affects the nature of VC investing, have eluded an analysis in the earlier literature.

The basic assumption will be that the equilibrium return $R$ to new ventures declines as more start-ups successfully mature to production stage. Given sufficiently many VCs, we may abstract from strategic interactions and assume that they behave as competitive price-takers. With large numbers, the probability $p$ is equal to the fraction of all start-ups that actually succeed in equilibrium. Focusing on symmetric cases with $N$ VCs in the industry and each one mentoring $n$ firms, we have an aggre-

gate of $p n N$ successful firms. Each firm is assumed to produce one unit of output, if successful. The market output (supply) is thus given by $p(a) n N$. We may then interpret venture returns as the market-clearing price $R$ for industry output. If output sells at a price $R$, then this is the return to a firm producing one unit of output. We are left 
to specify the demand of consumers for these products. We deliberately keep the demand function simple and abstract from market uncertainty, network externalities and other aspects of demand for innovative goods. Demand is simply a downward sloping function $D=\phi R^{-\eta}$ of the market price $R$ where $\phi>0$ is a demand shift parameter and $\eta>0$ is the price elasticity of market demand. ${ }^{16}$ Some of the comparative static results will depend on whether the price elasticity is smaller or larger than one. In industry equilibrium, price must adjust to equate market supply and demand,

$$
\phi R^{-\eta}=p(a) n N
$$

To identify how the short-run equilibrium with a fixed number of VCs is affected by supply and demand shocks, we log-linearize (13) at the initial equilibrium position,

$$
\eta \hat{R}=\hat{\phi}-\hat{N}-\hat{\alpha}-(1-\theta) \hat{a}-\hat{n}
$$

In short-run equilibrium, the number of VCs is exogenous. The comparative statics is then determined by three simultaneous equations (14), (9) and (6) in three unknowns, $\hat{R}, \hat{n}$, and $\hat{a}$. We now discuss how an increase in venture returns due to an exogenous demand shock affects the nature and evolution of the VC sector. The following propositions also report the results for various supply shocks to which we turn in subsequent subsections.

Consider now an exogenous demand shock which directly raises returns by $\eta \hat{R}=\hat{\phi}$, see (14). Higher returns feed back on supply since VCs find it profitable to attract more firms which boosts supply by $\hat{n}=\zeta_{R} \hat{R}$ as noted in (9). A higher return tends to encourage managerial support if the number of firms in the portfolio is given, see (6). The dilution of advice on account of a larger number of portfolio firms dominates, however, and makes projects more risky in the end (Lemma 1). Substituting $\hat{n}=\zeta_{R} \hat{R}$ into (6) gives, indeed, $\hat{p}=(1-\theta) \hat{a}=\frac{1-\theta}{(1-s)^{\Psi}}[\hat{R}-(1-s) \varepsilon \hat{n}]=-\hat{R}$, and shows that a smaller fraction of firms survives the start-up phase. Including these supply reactions in (14), the equilibrium return eventually settles at $\lambda \hat{R}=\hat{\phi}$ where $\lambda>0 .{ }^{17}$ In competitive equilibrium with an exogenous number of VCs, a demand shift thus boosts venture returns. Although a demand shock does not directly affect individual decisions, subject to given returns, a VC does respond to increased venture returns by adding firms to her portfolio. With more firms to attend, she advises each single one less intensively and accepts a higher risk of project failure. It turns out that contracts are not affected in equilibrium. While increased risk calls for a higher profit share of the entrepreneur, higher returns allow for a lower share such that the net effect just cancels.

\footnotetext{
${ }^{16}$ Such a demand function may be rationalized in terms of separable preferences over this industry's output and other goods, see Keuschnigg and Nielsen (2002), for example.

${ }^{17}$ As noted in (B.1), we have $\lambda \equiv \eta-1+\zeta_{R}>0$, since $R$ raises demand by $\eta \hat{R}$ and supply by $\left(\zeta_{R}-1\right) \hat{R}$, where $\zeta_{R}-1=\frac{1+\theta \varepsilon}{(1-\theta) \varepsilon}>0$ by use of $(9 \mathrm{~b})$. All A, B, C equations refer to the separate mathematical appendix Kanniainen and Keuschnigg (2003a) which can be downloaded from www.iff.unisg.ch.
} 
Table 1

Exogenous number of VCs

\begin{tabular}{llllll}
\hline Equations & $(\mathrm{B} .1)$ & $(\mathrm{B} .3)$ & $(\mathrm{B} .4)$ & $(9 \mathrm{a})$ & $(\mathrm{B} .8,9)$ \\
\hline Dep. var. & $\hat{R}$ & $\hat{n}$ & $\hat{a}$ & $\hat{s}$ & $\hat{\pi}$ \\
\hline$\hat{\phi}-\hat{N}$ & + & + & - & 0 & + \\
$\hat{\alpha}$ & - & $+^{*}$ & $-^{*}$ & 0 & $+^{*}$ \\
$\hat{\gamma}$ & + & $-^{*}$ & - & 0 & $-^{*}$ \\
$\hat{I}$ & + & - & + & - & $-?$ \\
$\hat{c}_{f}$ & 0 & 0 & 0 & 0 & - \\
\hline
\end{tabular}

Note: $\mathrm{A} *$ indicates that sign changes if $\eta<1$. A hat denotes a percentage change. Notation: $R$ venture return, $n$ number of portfolio companies, $a$ advice, $s$ entrepreneur's equity share, $\pi$ VC profit, $N$ number of $\mathrm{VC}$ funds, $\phi$ demand shift parameter, $\alpha$ managerial skill, $\gamma$ managerial effort cost, $I$ start-up investment cost, $c_{\mathrm{f}}$ fixed cost of $\mathrm{VC}$ fund.

Proposition 5 (Short-run Equilibrium). With an exogenous number of VCs, the comparative static effects of demand and supply shocks are as given in Table 1.

Proof. See mathematical appendix, Kanniainen and Keuschnigg (2003a). A column gives the short-run response of a dependent variable to the shocks listed in the first column. The first line locates the corresponding equation in the appendix which also allows to retrieve the magnitude of the elasticities.

Since funding and mentoring start-up companies requires much experience, new $\mathrm{VC}$ funds cannot be established in short order to accommodate an accelerating rate of business formation. With a fixed number of VCs $(\hat{N}=0)$, a demand shock $\hat{\phi}$ makes $\mathrm{VC}$ investing rather profitable and creates rents, $\hat{\pi}>0$. With sustained profit opportunities, new VCs should appear and promote the expansion of the industry. According to the first column of Table 1 , entry $\hat{N}>0$ spoils returns on new ventures which, in turn, cuts into profits and makes further entry increasingly unattractive. Entry stops when profit opportunities are exhausted. In solving for the long-run equilibrium with free entry, we first derive the effect on the return $R$ which satisfies the zero profit condition. We then investigate how such changes to venture returns affect managerial advice, profit sharing, and portfolio size. Finally, we substitute these responses together with the price effect $\hat{R}$ into the market condition (14), see (B.1) of the mathematical appendix, and obtain the number of VCs that are sustained in the free entry equilibrium.

Proposition 6 (Long-run Equilibrium). With free entry of competitive VCs, the comparative static effects of demand and supply shocks are as given in Table 2.

Proof. See Kanniainen and Keuschnigg (2003a), part C. The first line in Table 2 locates the corresponding equations which also report the elasticities.

The short-run equilibrium of the VC industry reflects the scarce supply of experienced VCs who can fund only a limited number of start-up firms. According to the 
Table 2

Free entry of VCs

\begin{tabular}{llllll}
\hline Equations & $(\mathrm{C} .1)$ & $(\mathrm{C} .4)$ & $(\mathrm{C} .5)$ & $(9 \mathrm{a})$ & $(\mathrm{C} .2,3)$ \\
\hline Dep. var. & $\hat{R}$ & $\hat{n}$ & $\hat{a}$ & $\hat{s}$ & $\hat{N}$ \\
\hline$\hat{\phi}$ & 0 & 0 & 0 & 0 & + \\
$\hat{\alpha}$ & - & 0 & 0 & 0 & $+^{*}$ \\
$\hat{\gamma}$ & + & 0 & - & 0 & $-^{*}$ \\
$\hat{I}$ & + & $?$ & - & - & $-?$ \\
$\hat{c}_{f}$ & + & + & - & 0 & - \\
\hline
\end{tabular}

Note: $\mathrm{A}^{*}$ indicates that sign changes if $\eta<1$. A hat denotes a percentage change. Notation: $R$ venture return, $n$ number of portfolio companies, $a$ advice, $s$ entrepreneur's equity share, $\pi$ VC profit, $N$ number of $\mathrm{VC}$ funds, $\phi$ demand shift parameter, $\alpha$ managerial skill, $\gamma$ managerial effort cost, $I$ start-up investment cost, $c_{\mathrm{f}}$ fixed cost of $\mathrm{VC}$ fund.

first line of Table 1, increased market opportunities for start-up firms on account of a positive demand shock are thus mainly felt in higher venture returns, larger portfolios, but less managerial support that can be extended to each firm. VC firms earn rents on their scarce resource as higher venture returns boost profits. Such rents will eventually succeed to attract new VCs to the industry and thereby relax the constraint on managerial support. With ever more VC backed firms crowding the market, entry depresses venture returns and increasingly squeezes VC profits. Entry continues until rents are fully dissipated in the long-run competitive equilibrium, implying $\hat{R}=0$. The demand shift is thus fully offset by entry of $\hat{N}=\hat{\phi}$ additional VCs which keeps returns at their initial level. Since a demand shift affects VC investing exclusively via the price channel but has otherwise no direct implications for managerial advice, portfolio size and profit shares, these variables must also return to their initial values, as is noted in the $\hat{\phi}$-line of Table 2 .

The analysis of demand shocks in Propositions 5 and 6 demonstrates an important adjustment pattern that reflects Lerner's (2002a) empirical account of the value added of $\mathrm{VC}$ in boom and bust periods. When new and innovative businesses are started at an accelerating rate, short-run VC investing can expand only if incumbent VCs finance more firms. With a fixed number of VCs, the quality of VC finance must first deteriorate on account of Lemma 1. As advice gets diluted, the rate of business failure is relatively higher in the short-run. Once entry of VCs occurs, each individual one is able to consolidate her portfolio and concentrate on a smaller number of firms which she advises more carefully. Only in the long-run is the quality of VC investing restored again. Note, however, that Proposition 4 holds irrespective of whether VC finance yields a positive surplus or not. The degree of managerial support per firm and the size of $\mathrm{VC}$ portfolios are inefficiently small both in the short and the longrun industry equilibrium.

\subsection{VC experience}

Experienced VCs are more successful in adding value to their firms and score a higher success rate with the same number of consulting hours. As more start-ups 
turn out successful, market supply expands by $\hat{\alpha}$ in (14). More sophisticated VCs should also like to include a larger number of firms in their portfolio, $\hat{n}=\zeta_{R} \hat{\alpha}$ in (9). For a given number of portfolio firms, more experience would encourage further advisory effort. The expansion of the portfolio, however, dilutes advice per firm to an extent that dominates the overall reaction. To see this, substitute $\hat{n}=\zeta_{R} \hat{\alpha}$ into (6) and use (9b) and (B.2), $(1-\theta) \hat{a}=\frac{1-\theta}{(1-s)^{\Psi}}[\hat{\alpha}-(1-s) \varepsilon \hat{n}]=-\hat{\alpha}$. Since each consulting hour is more effective, the $\mathrm{VC}$ actually cuts back the pure quantity of advice to each firm, but achieves the same success probability $\hat{p}=\hat{\alpha}+(1-\theta) \hat{a}=0$. With these results, supply expands by $\hat{n}=\zeta_{R} \hat{\alpha}$ in (14) and the market price must fall. Declining venture returns on account of market saturation discourage VC activity, however, and result in the end in a more moderate reduction of returns equal to $\hat{R}=-\left(\zeta_{R} / \lambda\right) \hat{\alpha}$, see (B.1) and Table 1. While more experience, subject to a given return, induces VCs to expand portfolios and restrict the level of advice (although each consulting unit is now more effective), declining equilibrium returns work in the opposite direction. If venture returns fall only to a minor degree in equilibrium, the $\mathrm{VC}$ will acquire a larger number of portfolio companies and allocate a smaller number of consulting hours to each one, as indicated in the $\hat{\alpha}$-line of Table 1 . This is the case if the price elasticity of demand is large, $\eta>1$. A small price reduction then suffices to generate a large increase in demand which easily absorbs the increased supply from more effective VC support. If the price elasticity is rather small, venture returns must fall a lot to restore equilibrium which changes the starrred signs noted in Table 1.

The same case distinction carries over to short-run VC rents and, therefore, to the incentives for entry and exit. More sophisticated financiers succeed to bring a larger fraction of start-ups to the market. A higher success rate on account of more experience directly boosts VC profits but on the other hand depresses the market price. The net effect on short-run profits is shown to be positive if the demand elasticity is large, $\eta>1$, such that equilibrium prices, or venture returns, fall to a minor extent only. As $\hat{N}=(\eta-1) \hat{\alpha}$ new VCs emerge, prices must fall even further, i.e. by a total amount of $\hat{R}=-\hat{\alpha}$ in the long-run, see (C.1). Although more experience encourages, for given project returns, larger portfolios, more intensive advice and smaller equity stakes for entrepreneurs, such incentives are completely offset in the long-run by the erosion of venture returns.

\subsection{Cost of advice}

VC investing may become more difficult due to government regulations and red tape, unpredictable and rapidly changing market conditions etc. For a given number of portfolio companies, VCs will then find it more costly to achieve a desired success rate. Quite intuitively, higher effort cost leads financiers to consolidate their portfolio, $\hat{n}=-\zeta_{\gamma} \hat{\gamma}$ in (9), and to cut back on advice per firm as well. On the other hand, the quality of advice benefits from VCs concentrating on fewer firms. Substituting $\hat{n}=-\zeta_{\gamma} \hat{\gamma}$ into (6) and using $\zeta_{\gamma}=1 / \varepsilon$ as given in $(9 \mathrm{~b})$, the net effect on managerial support is seen to be exactly zero, $(1-\theta) \hat{a}=-\frac{1-\theta}{\Psi}(\hat{\gamma}+\varepsilon \hat{n})=0$. Consequently, VC investing contracts on account of smaller company portfolios, leading to an increase 
in market price and venture returns. The feed back from a higher equilibrium return encourages portfolio expansion at the cost of advice. In the end, a VC finances fewer firms and also provides less managerial support to each one, see Table 1 . If the price elasticity $\eta$ is small, however, venture returns must increase strongly to restore equilibrium which overturns the short-run effect on portfolio size while the effect on advice is robust. Again, the equilibrium profit share remains unaffected due to offsetting influences. Since VCs tolerate higher project risk by cutting back advice, entrepreneurs ask for a higher profit share. On the other hand, a higher price makes them accept a lower share by (3ii). The two effects cancel in (7).

Higher managerial costs result in smaller profit margins while higher equilibrium returns boost profits. The net effect in Table 1 depends on the magnitude of the demand elasticity. With $\eta>1$, equilibrium returns rise only moderately, leaving effort costs to erode VC surplus. The subsequent exit of VCs leads to a supply contraction which magnifies the initial price increase. While higher effort cost per se causes VCs to advise a smaller number of start-up firms as indicated by (9), more profitable projects on account of rising venture returns lead them to restore the initial portfolio size, leaving the number of portfolio companies unchanged in the long-run, see Table 2. With the dilution of advice effect being eliminated, the reduction in managerial support is still negative but less pronounced than in the short-run. Reflecting the adjustment of managerial advice, start-up investment risk increases by more in the short-run than in the long-run. The incentive compatible equity share of entrepreneurs is affected neither instantaneously nor after entry is completed.

\subsection{Start-up investment cost}

Start-up investment may become more capital intensive. When financiers must incur higher start-up costs, they respond by cutting the number of portfolio companies. As they concentrate on fewer firms, managerial advice per firm is higher and thereby helps to contain the failure rate. With higher expected return on account of lower risk, the entrepreneurs' profit share can be reduced. The net effect on industry supply of smaller portfolios but larger survival rates is negative and boosts the market price as in Table 1. VC investing is likely to be less profitable in the shortrun, see the discussion of (B.9). Since entrepreneurs are assumed to have no own funds, the VC must finance the entire start-up cost. On the other hand, higher venture returns and a larger own profit share props up profits. This effect, however, is unlikely to dominate.

Responding to diminishing rents, part of the VCs will leave the sector. Exit further boosts the market price until the remaining investors break even. Venture returns in the free entry equilibrium must thus exceed short-run values. Via this effect, exit of VC firms makes the remaining investors expand their portfolios at the cost of less intensive advice which reverses the short-run adjustment to higher start-up cost in Table 1. For this reason, the net effects on managerial advice and portfolio size in the long-run equilibrium become ambiguous in Table 2. 


\subsection{Entry cost}

Finally, more rapid innovation, faster industry restructuring, government regulations and other uncertainties can also inflate general overhead expenses for market studies and raise the cost of setting up a VC fund. Such cost is not specifically related to any individual start-up company but must be covered by revenues from the entire portfolio of firms. Since fixed costs are sunk at later stages of the VC cycle, they cannot directly affect managerial advice, profit sharing and portfolio size in the shortrun. In cutting profits, however, inflated fixed costs restrain entry of financiers. Fewer VC backed investments drive up venture returns until VCs break even again. We infer that the industry sustains a smaller number of VCs, see Table 2. By (9), VCs expand their portfolio of firms when projects become more valuable, $\hat{n}=\zeta_{R} \hat{R}$. Even though a higher return encourages advice, the larger portfolio dilutes advice to an extent that managerial support per firm declines. ${ }^{18}$ Projects become more risky. Profit sharing remains invariant since increased risk and higher project value exactly offset each other in affecting incentives of entrepreneurs.

\section{Conclusions}

Our results advocate the view that the critical resource in the development of the VC industry is the managerial expertise and knowledge of experienced VCs. The specialized human capital of VCs isn't easily acquired but takes time to develop. To emphasize this point, we consider a short-run equilibrium where the number of VCs is fixed. The scarcity of the managerial resource should create rents which eventually attract new VCs who compete them away in the long-run equilibrium. When more VCs are ready to finance start-up entrepreneurs, they should find it optimal to consolidate their portfolio and advise each company more intensively.

Our results obtained in Tables 1 and 2 lead to a number of testable implications. For example, investor experience and know how such as age of $\mathrm{VC}$ funds or other measures of VC skills should result in them being more closely involved. It should have a significant impact on the quality of advice, leading to smaller failure rates or to a better performance of VC backed firms. From this perspective, there might be differences between the performance of the US and the European VC sectors. Comparing the size of company portfolios and the speed of market entry could shed light on the dynamics of innovative industries in those economies. The results on the interaction of adjustment of rents and market entry predicts that expansion of the VC sector will first be constrained by a shortage of investor skills, leading to larger portfolios at the expense of quality. ${ }^{19}$ Eventually, the industry should be able to at-

\footnotetext{
${ }^{18}$ Substituting $\hat{n}=\zeta_{R} \hat{R}$ into (6) and using (9b) and (B.2), we get $\hat{a}=\frac{\hat{R}-(1-s) \hat{n}}{(1-s) \Psi}=-\frac{\hat{R}}{1-\theta}$.

${ }^{19}$ Lerner (2002a, pp. 35-36) finds indeed that the impact of VC on innovation declines in boom periods but is larger in normal periods. Also consistent with our arguments, Cumming and MacIntosh (2003a) find that Canadian Labour Sponsored Venture Capital Funds have systematically underperformed, citing as a principal reason the lack of specialized managerial skills and training on the part of LSVCC managers.
} 
tract specialized managerial talent for a larger number of highly professional VC funds. VC portfolios should then become smaller and more focused, with more VC value added to each individual company. The data that are available so far, do not allow for an empirical analysis of many of the implications that arise from our results. ${ }^{20}$ It is hoped that, in the future, more detailed data on VC portfolios become available to facilitate the empirical investigation of the implications which arise from our results, such as the trade-off between portfolio size and managerial advice. However, given the tax and institutional differences across countries, empirical tests of the model and estimates of the supply and demand of VC may yield quite different degrees of fit.

There are a number of aspects of our model that would warrant further analytical work. A worthwhile extension might be to relax our simplifying assumption that entrepreneurs are in perfectly elastic supply. In fact, the VC community often complains about the lack of skilled entrepreneurs. The growth of innovative start-up investment might not only by constrained by the scarce supply of VC investment skills, as our paper emphasizes, but also by a lack of spirited entrepreneurs with promising ideas. This calls for modeling an inelastic supply of entrepreneurs. Further theoretical and empirical work could explore the implications of having continuous effort by the entrepreneur and of allowing for a more dynamic relationship between entrepreneurs and VCs. A richer framework along these lines would probably give rise to a role for staging, syndication and covenants in overcoming incentive problems in VC finance. Finally, our welfare result on inefficiently low VC advice and overly small portfolios calls for an investigation of the role of public policy in variations of VC models as ours. ${ }^{21}$

\section{Acknowledgements}

Drafts of the paper were presented at the Universities of Saarland, Freiburg, St. Gallen and Helsinki, the European Financial Management Association Meeting in Lugano (2001) and the European Economic Association Meeting in Lausanne (2001). We appreciate stimulating comments by D. Bös, G. Chiesa, D. Cumming, J. Eichberger, T. Gehrig, W.L. Megginson and P. Strobel. We are particularly grateful to an anonymous referee whose very constructive comments greatly helped to further improve the paper.

\section{References}

Admati, A.R., Pfleiderer, P., 1994. Robust financial contracting and the role of venture capitalists. Journal of Finance 49, 371-402.

\footnotetext{
${ }^{20}$ See, however, the empirical study of Cumming (2001a) on the determinants of VC portfolio size.

${ }^{21}$ Lerner (2002b) offers an illuminating informal discussion in this direction while Keuschnigg (2002) presents a formal analysis of tax policy based on the partial equilibrium version of this model. A rigorous analysis of the real and welfare effects of public policy in industry equilibrium is missing.
} 
Aghion, P., Bolton, P., 1992. An incomplete contracts approach to financial contracting. Review of Economic Studies 59, 473-494.

Aghion, P., Tirole, J., 1994. The management of innovation. Quarterly Journal of Economics 109, 11851209.

Aghion, P., Bolton, P., Tirole, J., 2000. Exit options in corporate finance: Liquidity versus incentives, University College London, Princeton University and IDEI, Toulouse, Working Paper.

Barry, C., 1994. New directions in research on venture capital finance. Journal of the Financial Management Association 23, 3-15.

Bascha, A., Walz, U., 2001. Financing practices in the german venture capital industry: An empirical assessment, University of Tübingen, Working Paper.

Bergemann, D., Hege, U., 1998. Venture capital financing, moral hazard, and learning. Journal of Banking and Finance 22, 703-735.

Berglöf, E., 1994. A control theory of venture capital finance. Journal of Law, Economics and Organization 10, 247-267.

Bottazzi, L., Da Rin, M., 2002. Venture capital in Europe: Euro.nm and the financing of European innovative firms. Economic Policy 34, 231-269.

Casamatta, C., 2002. Financing and advising: Optimal financial contracts with venture capitalists, CEPR DP 3475. Journal of Finance, forthcoming.

Chemmanur, T.J., Chen, Z., 2001. Angels, venture capitalists, and entrepreneurs: A dynamic model of private equity financing, Boston College, Carroll School of Management, and University of Pennsylvania, Wharton School, Working Paper.

Cornelli, F., Yosha, O., 2003. Stage financing and the role of convertible securities. Review of Economic Studies $70,1-32$.

Cumming, D.J., 2001a. The determinants of venture capital portfolio size: Empirical evidence, University of Alberta School of Business, Working Paper.

Cumming, D.J., 2001b. United States venture capital financial contracting: Evidence from investments in foreign securities, University of Alberta School of Business, Working Paper.

Cumming, D.J., 2002. Contracts and exits in venture capital finance, University of Alberta School of Business, Working Paper.

Cumming, D.J., MacIntosh, J.G., 2003a. Canadian labour sponsored venture capital corporations: Bain and boon? In: Ginsberg, A., Hasan, I. (Eds.), New Venture Investment. Elsevier Science, Amsterdam.

Cumming, D.J., MacIntosh, J.G., 2003b. A cross country comparison of full and partial venture capital exits. Journal of Banking and Finance 27 (3), 511-548.

Garmaise, M., 2000. Informal investors and the financing of entrepreneurial projects, University of Chicago, Working Paper.

Gilson, R.J., Schizer, D.M., 2002. Understanding venture capital structure: A tax explanation for convertible preferred stock, Columbia Law School, Working Paper.

Gompers, P.A., 1995. Optimal investment, monitoring, and the staging of venture capital. Journal of Finance 5, 1461-1489.

Gompers, P.A., Lerner, J., 1996. The use of covenants: An empirical analysis of venture partnership agreements. Journal of Law and Economics 39, 463-498.

Gompers, P.A., Lerner, J., 1999. The Venture Capital Cycle. MIT Press, Cambridge, MA.

Gorman, M., Sahlman, W.A., 1989. What do venture capitalists do? Journal of Business Venturing 4, 231248.

Hellmann, T., 1998. The allocation of control rights in venture capital contracts. Rand Journal of Economics 29, 57-76.

Hellmann, T., Puri, M., 2000. The interaction between product market and financing strategy: The role of venture capital. Review of Financial Studies 13, 959-984.

Hellmann, T., Puri, M., 2002. Venture capital and the professionalization of start-ups: Empirical evidence. Journal of Finance 57, 169-197.

Inderst, R., Müller, H.M., 2002. The effect of capital market characteristics on the value of start-up firms, CEPR DP 3203, revised version. Journal of Financial Economics, forthcoming. 
Kanniainen, V., Keuschnigg, C., 2003a. Start-up Investment With Scarce Venture Capital Support: Mathematical Appendix, http://www.iff.unisg.ch, Page Research/DP Public Finance No. 0101.

Kanniainen, V., Keuschnigg, C., 2003b. The optimal portfolio of start-up firms in venture capital finance. Journal of Corporate Finance 9, 521-534.

Kaplan, S.N., Strömberg, P., 2000. Financial contracting theory meets the real world: An empirical analysis of venture capital contracts, NBER working paper series 7660 .

Kaplan, S.N., Strömberg, P., 2001. Venture capitalists as principals: Contracting, screening, and monitoring. American Economic Review, Papers and Proceedings 91, 426-430.

Keuschnigg, C., 2002. Taxation of a venture capitalist with a portfolio of firms, University of St. Gallen, IFF-DP 0202, and CESifo-DP 813.

Keuschnigg, C., 2003. Optimal public policy for venture capital backed innovation, University of St. Gallen and CEPR DP 3850.

Keuschnigg, C., Nielsen, S.B., 2003. Tax policy, venture capital, and entrepreneurship. Journal of Public Economics 87, 175-203.

Keuschnigg, C., Nielsen, S.B., 2002. Start-ups, venture capitalists, and the capital gains tax, CEPR DP 3263 and CESifo DP 742. Journal of Public Economics, forthcoming.

Kortum, S., Lerner, J., 2000. Assessing the contribution of venture capital to innovation. Rand Journal of Economics 31, 674-692.

Lerner, J., 1994. The syndication of venture capital investments. Financial Management 22, 16-27.

Lerner, J., 1995. Venture capitalists and oversight of privately-held firms. Journal of Finance 50, 301-318.

Lerner, J., 2002a. Boom and bust in the venture capital industry and the impact on innovation. Federal Reserve Bank of Atlanta Economic Review 2002 (4), 25-39.

Lerner, J., 2002b. When bureaucrats meet entrepreneurs: The design of effective 'Public Venture Capital' programmes. Economic Journal 112, F73-F84.

Lerner, J., Schoar, A.M.S., 2002. The illiquidity puzzle: Theory and evidence from private equity, Sloan School of Management, MIT Working Paper No. 4378-02.

Marx, L., 1998. Efficient venture capital financing combining debt and equity. Review of Economic Design 3, 371-387.

Michelacci, C., Suarez, J., 2002. Business creation and the stock market, CEPR DP 3513. Review of Economic Studies, forthcoming.

Neher, D., 1999. Staged financing: An agency perspective. Review of Economic Studies 66, 255-274.

Norton, E., Tenenbaum, B.H., 1993. Specialization versus diversification as a venture capital investment strategy. Journal of Business Venturing 8, 431-442.

Reid, G.C., Terry, N.G., Smith, J.A., 1997. Risk management in venture capital investor-investee relations. European Journal of Finance 3, 27-47.

Repullo, R., Suarez, J., 1999. Venture capital finance: A security design approach, CEPR DP No. 2097.

Sahlman, W.A., 1990. The structure and governance of venture-capital organizations. Journal of Financial Economics 27, 473-521.

Sandler, D., 2001. The tax treatment of employee stock options: Generous to a fault. Canadian Tax Journal 49, 259-302.

Schmidt, K.M., 2002. Convertible securities and venture capital finance. Journal of Finance, forthcoming.

Schwienbacher, A., 2002. An empirical analysis of venture capital exits in europe and in the United States, University of Namur, Working Paper.

Trester, J.J., 1998. Venture capital contracting under asymmetric information. Journal of Banking and Finance 22, 675-699. 